Research Article

\title{
Case Study and Numerical Simulation of Excavation beneath Existing Buildings
}

\author{
Hua-feng Shan $\mathbb{D}^{1,2,3}$ Shao-heng $\mathrm{He}^{2}{ }^{2}$ Yu-hua $\mathrm{Lu}^{3}{ }^{3}$ and Wei-jian Jiang ${ }^{3}$ \\ ${ }^{1}$ School of Civil Engineering and Architecture, Taizhou University, Taizhou 318000, China \\ ${ }^{2}$ Research Center of Coastal and Urban Geotechnical Engineering, Zhejiang University, Hangzhou 310058, China \\ ${ }^{3}$ Fangyuan Construction Group Co., Ltd., Taizhou 318000, China \\ Correspondence should be addressed to Hua-feng Shan; shanhf@zju.edu.cn
}

Received 9 July 2020; Revised 11 October 2020; Accepted 15 December 2020; Published 30 December 2020

Academic Editor: Hui Yao

Copyright ( $\odot 2020$ Hua-feng Shan et al. This is an open access article distributed under the Creative Commons Attribution License, which permits unrestricted use, distribution, and reproduction in any medium, provided the original work is properly cited.

Excavation beneath existing buildings may cause the superstructure to tilt and crack, which seriously affects the normal use of the superstructure. Due to the new working conditions of excavation beneath existing buildings, related case reports are rare and limited. In the case of No. 3 section basement construction project of Ganshuixiang, we monitored the excavation construction by burying test instruments at the designated location. Afterwards, Plaxis 3D finite element software was used to establish an underpinning pile-cap-excavation model, which can analyze the influence of different pile cutting sequences on the bearing behavior of new basement structural pillars. By comparing the in situ measurement data with the finite element model, it can be concluded that when the excavation depth rises, the axial force of the underpinning pile gradually increases, and the pile skin friction is slowly exerted from top to bottom. Different cutting sequences will influence the bearing behavior of the structural pillar. Moreover, the pile cutting process also significantly impacts its bearing behavior and the settlement behavior of the superstructure. Compared with the clockwise pile cutting sequence, the symmetrical pile cutting is more advantageous. In the whole process of the storey adding and reconstruction, the superstructure settlement is related to the working condition of digging and adding layers. In the stage from soil excavation to the concrete curing period of the structural pillar, it increases slowly with time and tends to be stable in the concrete curing period. However, in the pile cutting stage, the superstructure settlement increases sharply, and after pile cutting, it becomes stable.

\section{Introduction}

With the booming economy and urbanization, the size of cities continues to expand. In this process, some "urban diseases" begin to emerge, such as traffic jams and parking issues. The development of cities is limited by land resources, but high-rise development will only increase the density of buildings and reduce their ability to resist catastrophes. It makes urban development enter a vicious circle. However, the rational development of underground space finds a solution to the above problems. Under this background, underground projects such as underground parking lots and subways are being developed. As these underground projects all require a large amount of soil excavation, they inevitably change the original stress field there. Adverse consequences are caused, including cracking and differential settlement of surrounding buildings.

To this end, Chinese and foreign researchers have conducted in-depth research on this issue. For example, Sung et al. [1] made an analysis of the impact of subway tunnel excavation on various adjacent foundation buildings based on 2D and 3D finite element models. Zhang et al. [2,3] and Liu et al. [4] studied its influence on the pile foundation. Zheng et al. [5] analyzed the influencing factors, including spacing, pile foundation stiffness, pile top load, and pile end constraint, based on the measured data using finite element software. Similarly, Wang et al. [6] proposed a calculation method for additional deformation of adjacent buildings induced by the excavation of foundation pits. 
The above researchers have investigated the influence of soil excavation on surrounding architectures. However, in projects of excavation beneath existing buildings, constructors will excavate the soil layer under the existing building. Thus, the excavation and unloading of the soil will directly affect the foundation pile's bearing properties. Currently, some Chinese experts have investigated this problem. Gong et al. [7] and $\mathrm{Wu}$ et al. [8] explored the influence of excavation on the skin friction and the end friction of the existing pile, based on the underground garage expansion project in the Zhejiang Hotel. Moreover, Wu et al. [9] introduced a hyperbolic load transfer model to investigate the excavation's effect on the bearing properties of the existing single pile with the load transfer method. Later, Shan et al. [10] considered the complex pile-pile and pile-soil interactions between group foundation piles and used this method to study its effect on the pile top settlement performance of group foundation piles. In those projects based on soft soil areas in Hangzhou, a softening phenomenon might be triggered by the skin friction of the pile with the rise of excavation depth [11]. Therefore, Shan et al. [12] used the load transfer method to analyze the impact of the underground garage project in the Zhejiang Hotel on the pile top settlement behavior of the existing pile. They introduced the softening model of skin friction. In projects of excavation beneath existing buildings, the soil excavation will increase the free length of the foundation pile. It may cause buckling instability there and lead to catastrophic consequences. To this end, Shan et al. [13, 14] studied the calculation method and influencing factors of the critical load for the buckling and stability of foundation piles.

In summary, researchers have carried out plenty of theoretical studies on this topic. Due to the new working conditions of excavation beneath existing buildings, that is, the narrow construction surface and sufficient special construction machinery, the related case reports are rare and limited [15-17]. In the case of No. 3 section basement construction project of Ganshuixiang, we monitored the excavation construction by burying test instruments in situ. Then, the influences of soil excavation on the bearing behavior of the underpinning pile, different pile cutting sequences on the structural pillar's bearing behavior, and the excavation process on the settlement behavior of the superstructure were analyzed using the in situ measurement data. As the superstructure of the project has two floors and one floor locally, and the surrounding buildings are relatively dense, this study only considers the influence of dead load, such as the dead weight of the superstructure. The influence of wind load and seismic load is not discussed [18]. Afterwards, a 3D solid model of 7C cap-underpinning pileexcavation was established through Plaxis 3D finite element software, which can simulate the influence of different pile cutting sequences on the structural pillar's bearing properties. It provides guidance for related projects.

\section{Project Overview}

No. 3 section basement construction project of Ganshuixiang is located in Ganshuixiang, Zhakou Street, Shangcheng District,
Hangzhou, Zhejiang Province. It is adjacent to the White Pagoda Park Scenic Area. There are no high-rise buildings around the project. The north and south of this project are No. 2 section and No. 5 section of Ganshuixiang, respectively. The east is No. 4 section under construction, and the west is Cherry Hill. The specific layout is shown in Figure 1.

No. 3 section of Ganshuixiang has a two-storey frame structure (partially one-storey), no basement. Its total building height is $8.01 \mathrm{~m}$. As the load of the superstructure is small, an independent foundation under the pillar with a buried depth of $1.80 \mathrm{~m}$ is adopted. According to the survey report [19], No. 3 section basement construction project of Ganshuixiang is located in an area typical of soft soil. Its physical and mechanical properties are tabulated in Table 1, where $\gamma_{s}$ is the soil unit weight, $c$ is the cohesion, $\varphi$ is the angle of internal friction, $E_{s}$ is the compression modulus, and $\mu$ is Poisson's ratio.

No. 3 section of Ganshuixiang was completed in 2014. Soon, the owner discovered that the building had a problem of insufficient usable area. Therefore, it was decided to excavate a basement beneath the existing building. After completion, about $1700 \mathrm{~m}^{2}$ of the usable area was added. No. 3 section basement construction project of Ganshuixiang started in November 2014, and the main structure construction of the basement was completed in August of the following year.

\section{Profile of Excavation beneath Existing Buildings}

At present, case reports of similar excavation projects are rare and limited [15-17]. Therefore, this section introduces the construction procedure of the project against the background of No. 3 section basement construction project of Ganshuixiang [20].

The construction process of the project is shown in Figure 2:

The specific construction technology is as follows.

(1) As the high pressure jet grouting pile can not only be used as the waterproof curtain but also can play the role of retaining soil. Hence, before soil excavation, different forms of jet grouting piles should be constructed around No. 3 section, as shown in Figure 3. At the same time, steel pipes with a $48 \mathrm{~mm}$ diameter and a $3 \mathrm{~mm}$ wall thickness were arranged in an equilateral triangle in the high pressure jet grouting pile. They can improve their bending strength.

(2) Generally speaking, in the foundation pit engineering, the precipitation depth should be greater than the excavation depth of soil [21]. This project requires the precipitation depth to be at least $0.50 \mathrm{~m}$ below the excavation face. Therefore, 23 wells with a $0.60 \mathrm{~m}$ diameter and a $7.0 \mathrm{~m}$ depth were arranged inside and around No. 3 section for precipitation, including 9 precipitation wells (D1) inside the pit and 14 precipitation wells outside the pits (D2).

(3) The excavation depth of the first soil layer was $1.80 \mathrm{~m}$, that is, the buried depth of the independent 


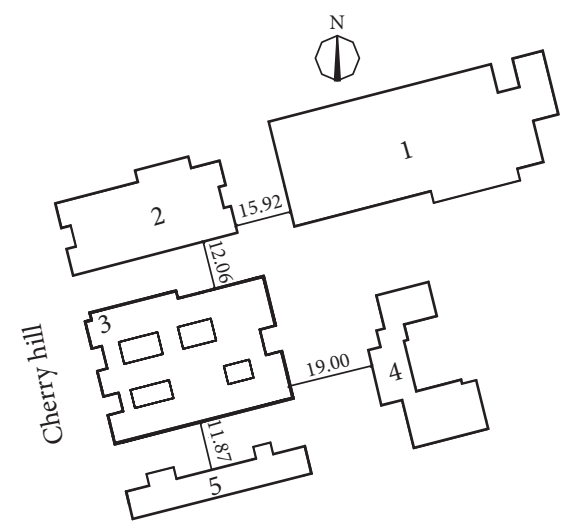

Figure 1: Overall arrangement of No. 3 section basement construction project of Ganshuixiang (unit: m). Note: 1-5 represent Nos. 1-5 sections of Ganshuixiang.

TABLe 1: Physical and mechanical nature of soils.

\begin{tabular}{lcccrr}
\hline Layer no. & Name & $\gamma_{s}\left(\mathrm{kN} / \mathrm{m}^{3}\right)$ & $c(\mathrm{kPa})$ & $\varphi\left(^{\circ}\right)$ & $E_{s}(\mathrm{MPa})$ \\
\hline (1)-0 & Miscellaneous fill & - & - & - & - \\
(1)-1 & Silty clay & 18.7 & 8.9 & 3.6 & 3.5 \\
(2) & Clay silt & 18.55 & 12.1 & 27.4 & 10.5 \\
(3) & Sludge & 16.15 & 8.5 & 2.9 & 0.35 \\
(4) & Gravelly silty clay & 19.00 & 40.00 & 13.80 & 0.35 \\
(10)-1 & Fully weathered sandstone & 19.77 & & 6.0 & 0.35 \\
(10)-2 & Highly weathered sandstone & & & 0.35 \\
(10)-3 & Moderately weathered sandstone & - & - & 0.35 \\
\hline
\end{tabular}

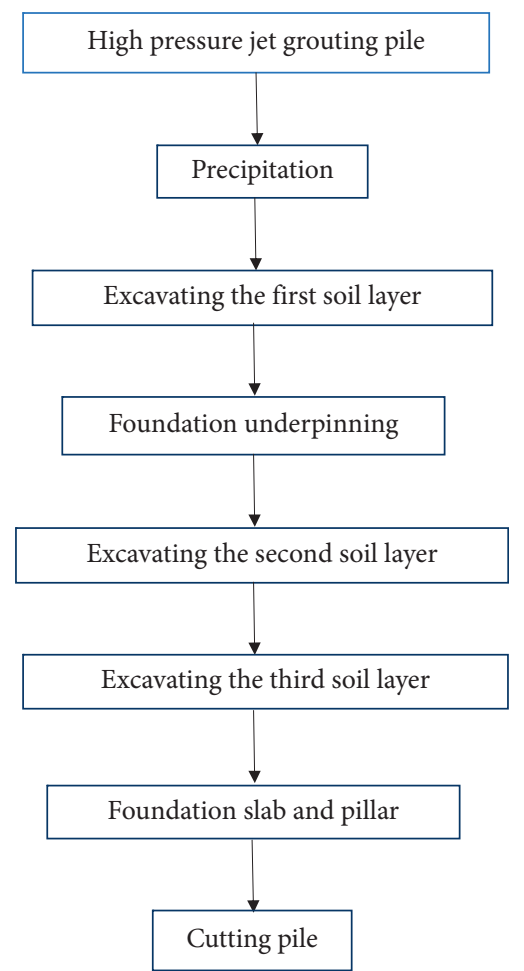

FIgURE 2: Construction flowchart of No. 3 section basement construction project of Ganshuixiang. 


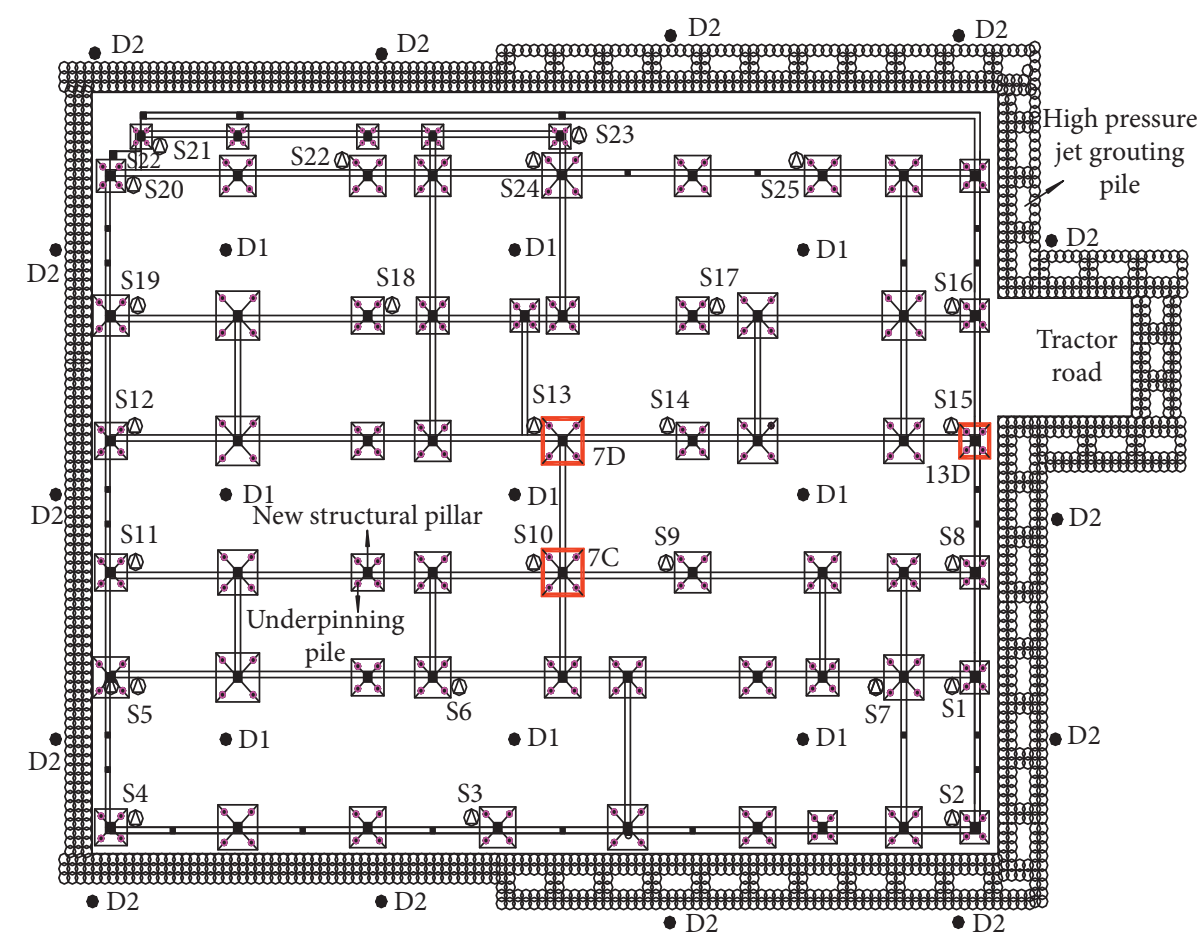

FIgURE 3: Plan of piles and monitoring points in No. 3 section basement construction project of Ganshuixiang. Note: (1) In the construction process, we monitored the piles and pillars at the caps of 7C, 7D, and 13D. (2) D1 and D2 are the dewatering well points. (3) S1-S25 are the subsidence monitoring points.

foundation. In soil excavation, it is advisable to use block segmentation excavation. The altitude difference of the excavation face should be controlled within $1.50 \mathrm{~m}$, and the slope should not be greater than $1: 1.5$. Afterwards, the first layer of soil nailing wall was constructed, as shown in Figure 4.

(4) The superstructure floor height of this project restricts the foundation underpinning equipment. Therefore, the foundation underpinning in this paper used a small drill to drill the hole to the designated elevation. Then, the steel pipe pile with a $250 \mathrm{~mm}$ outer diameter and an $8 \mathrm{~mm}$ wall thickness was placed down to the bearing stratum (10-2), as shown in Figure 5. In order to improve the compressive strength of the steel pipe pile, this project poured fine aggregate concrete inside the steel pipe pile, as shown in Figure 6. Finally, a floor slab was poured to form a whole to bear the load of the superstructure. Thus, the foundation underpinning was completed, as shown in Figure 7.

(5) The second layer of soil was excavated at $3.0 \mathrm{~m}$ deep. With the soil excavation around the pile, the soil constraint beside the pile gradually decreased. Under the axial load of the pile top, the foundation pile might buckle and lose stability [13, 14]. Therefore, when the excavation depth reached $3.0 \mathrm{~m}$, steel supports should be welded between the foundation piles, as shown in Figures 8 and 9, to prevent buckling instability of these piles. Afterwards, the second layer of soil nailing wall was constructed.
(6) The third layer of soil was excavated at $4.42 \mathrm{~m}$ deep, and the third layer of soil nailing wall was constructed. Afterwards, the basement cushion and foundation slab were poured. Then, the original independent foundation and foundation beam were removed. The new basement structural pillar was poured, with a section size of $0.45 \times 0.45 \mathrm{~m}^{2}$, as shown in Figures 9 and 10.

(7) As the structural pillar is the main vertical force transfer component, if the strength fails to reach the design value, cutting off the pile rashly will cause catastrophic consequences in the superstructure, such as tilt, cracking, and even collapse. Therefore, this project strictly followed the specification [22] for the maintenance cycle of concrete components.

(8) In order to improve the utilization rate of the new basement space, the underpinning pile should be removed in this project. First, the steel supports between the foundation piles should be removed. Then, we cut off parts of the steel pipe pile at the top and under the pile near the new basement foundation slab. The air pick was used to remove the fine aggregate concrete in the pipe, as shown in Figure 11(a). Finally, the whole pile cutting process was completed by pulling down the rope tied in the middle of the steel pipe pile, as displayed in Figure 11(b). Judging from the in situ pile cutting situation, the fine stone concrete at the pile top was well condensed, while the concrete under the pile was poorly condensed and was loose, as shown in 


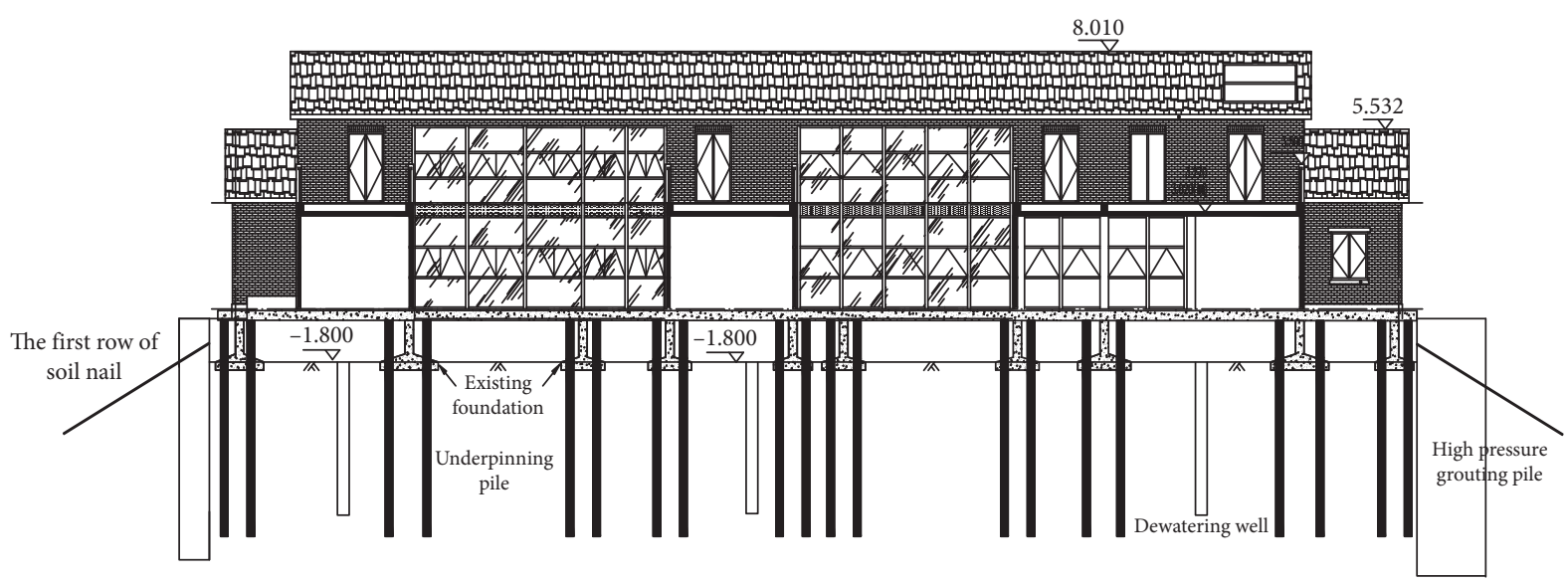

FIGURE 4: Excavation the first soil layer and construction underpinning pile (unit: $\mathrm{m}$ ).

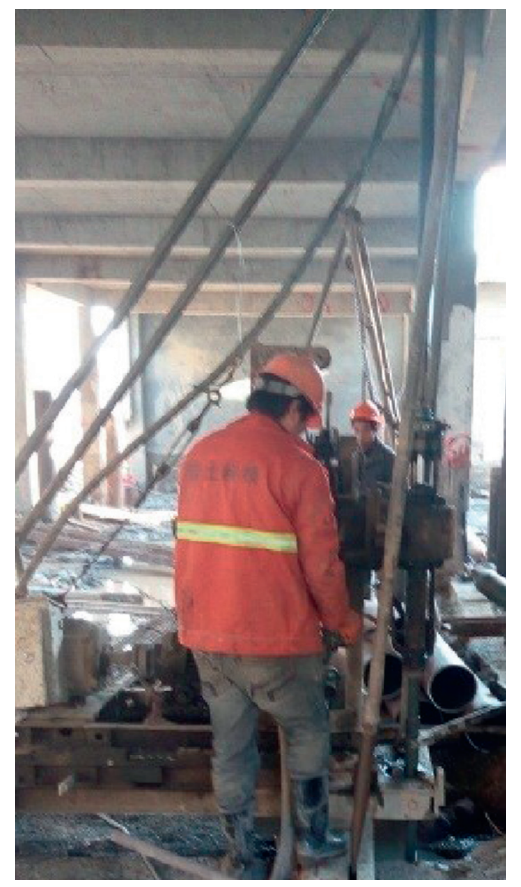

(a)

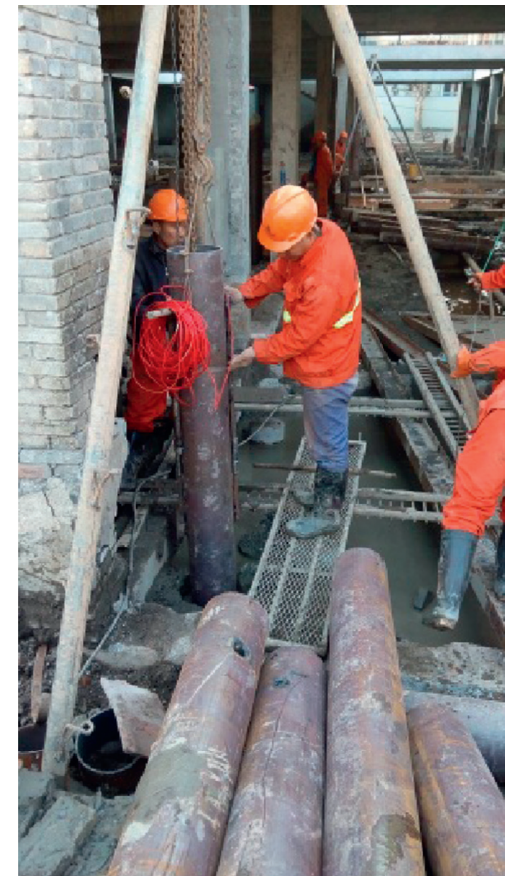

(b)

Figure 5: Predrill the steel pipe pile: (a) drill; (b) place down the pipe.

Figure 12. The reason may be related to the groundwater level.

At this point, the main structure of No. 3 section basement construction project of Ganshuixiang was completed, as shown in Figures 13 and 14.

\section{Construction Monitoring}

Due to the rare cases of similar excavation, the influences of soil excavation on the bearing behaviors of the underpinning pile and superstructure, and the influence of the pile cutting process on the bearing capacity of the structural pillar, have not been clarified. Therefore, in No. 3 section basement construction project of Ganshuixiang, the vibrating wire rebar strain gauge was welded beside the steel pipe underpinning pile at $7 \mathrm{C}, 7 \mathrm{D}$, and $13 \mathrm{D}$ caps and the middle position of the new basement structural pillar, respectively. They can monitor the influences of soil excavation on the underpinning pile's bearing properties and underpinning pile cutting on the new structural pillar, as shown in Figure 15. Additionally, 25 settlement monitoring points (S1 S25) were set at the corresponding positions of the first floor slab, as shown in Figure 3. They were used to monitor the influence of No. 3 section basement construction project of Ganshuixiang on the settlement behavior of the superstructure. According to the technical standard for monitoring of the building excavation engineering, during the 


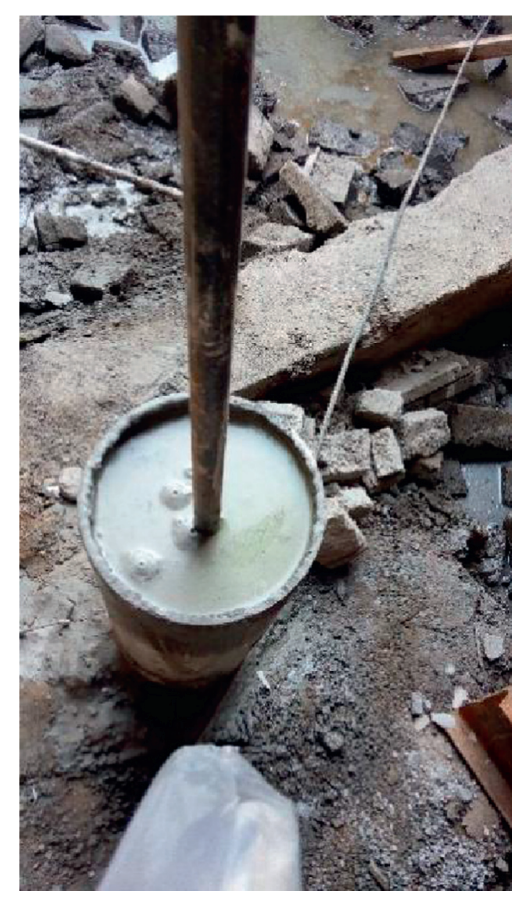

FIGURE 6: Underpinning pile after grouting.

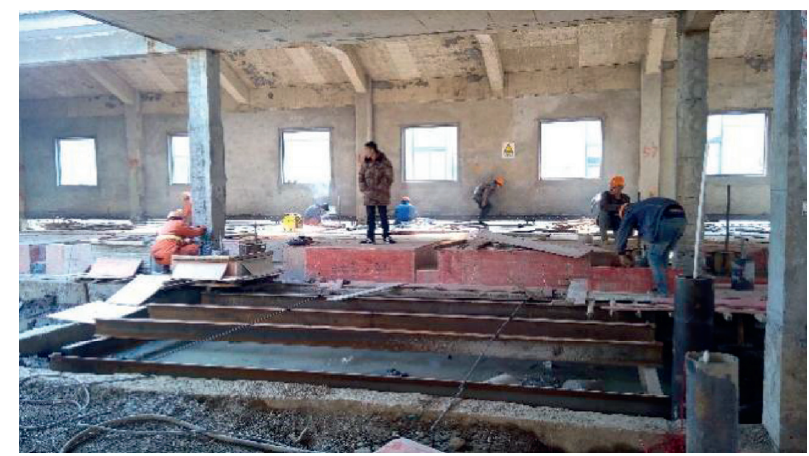

FIGURE 7: Formwork for the first floor.

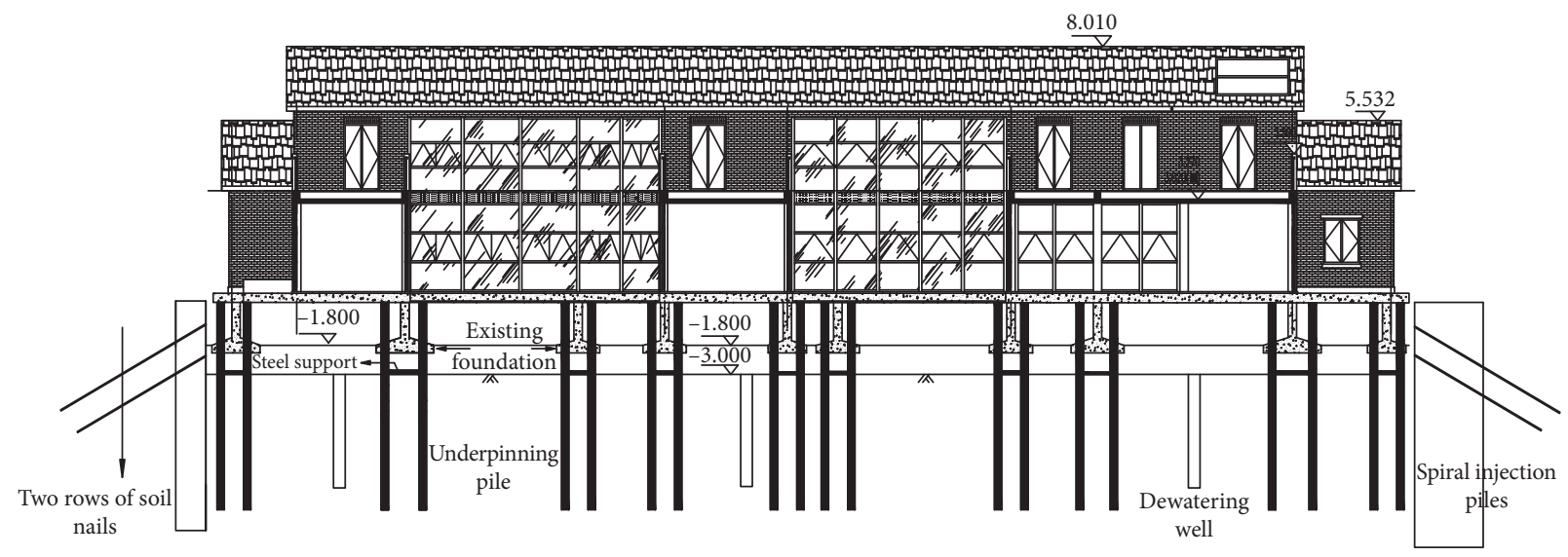

Figure 8: Excavating the second soil layer. 


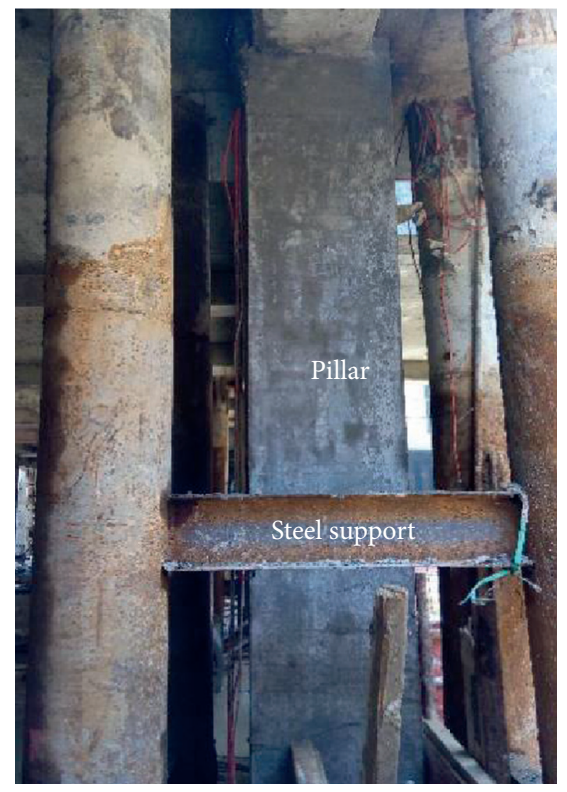

Figure 9: The structural pillar of the new basement and the steel support between piles.

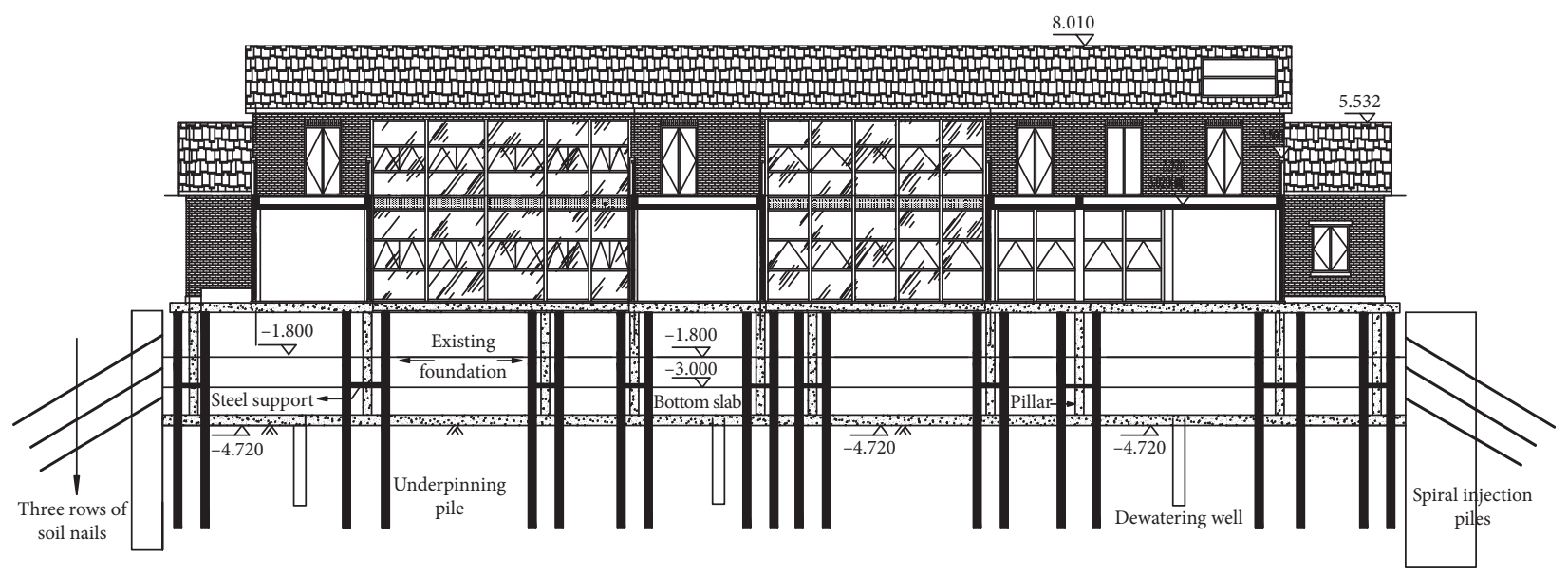

Figure 10: Excavating the third soil layer and pouring new structural pillar.

basement storey adding and reconstruction, the frequency of the superstructure settlement monitoring was once every two days, except during the Spring Festival holiday. The axial force of the underpinning pile was twice a day, once in the morning and afternoon. During the pile cutting period, the axial force of the underpinning pile and structural column was continuously monitored.

Due to the space limitation, the 7C cap is used in this paper as an instance to investigate the effect of excavation on the bearing behaviors of the underpinning pile and structural pillars. The layout of vibrating wire rebar strain gauges is shown in Figure 8.

By measuring the frequency variation value of the vibrating wire rebar strain gauge welded on the outside of the steel pile, the pile's axial force value at the corresponding depth can be converted as follows:
The axial force on the vibrating wire rebar strain gauge at the cross section $i$ is $P_{\text {sgi }}$ :

$$
P_{s g i}=K\left(F_{0}^{2}-F_{i}^{2}\right)
$$

where $K$ is the calibration coefficient of the gauge; $F_{0}$ is the gauge's initial frequency; $F_{i}$ is the vibration frequency of section $i$ under a certain load.

According to the elastic mechanics [23], the gauge's strain at the cross section $i$ is $\varepsilon_{\text {sgi }}$ :

$$
\varepsilon_{s g i}=\frac{P_{s g i}}{\left(E_{s g} A_{s g}\right)},
$$

where $A_{s g}$ and $E_{s g}$ are the sectional area and elastic modulus of the vibrating wire rebar strain gauge. 


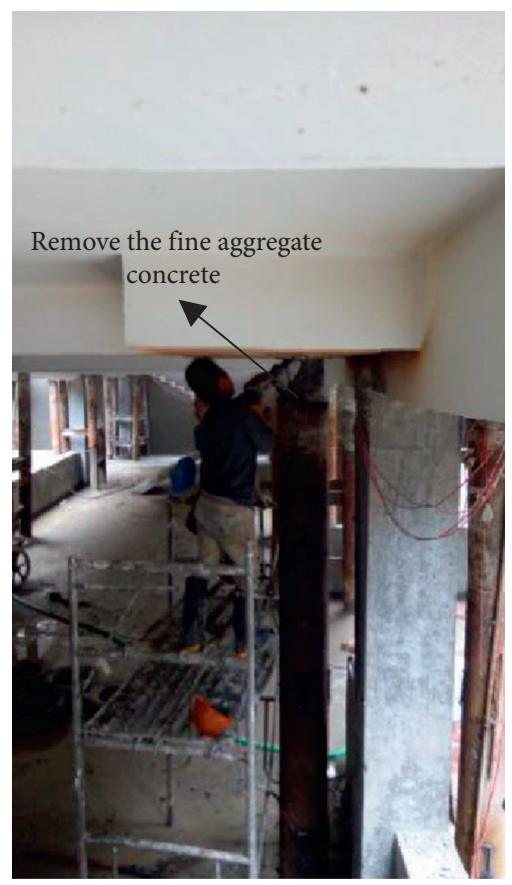

(a)

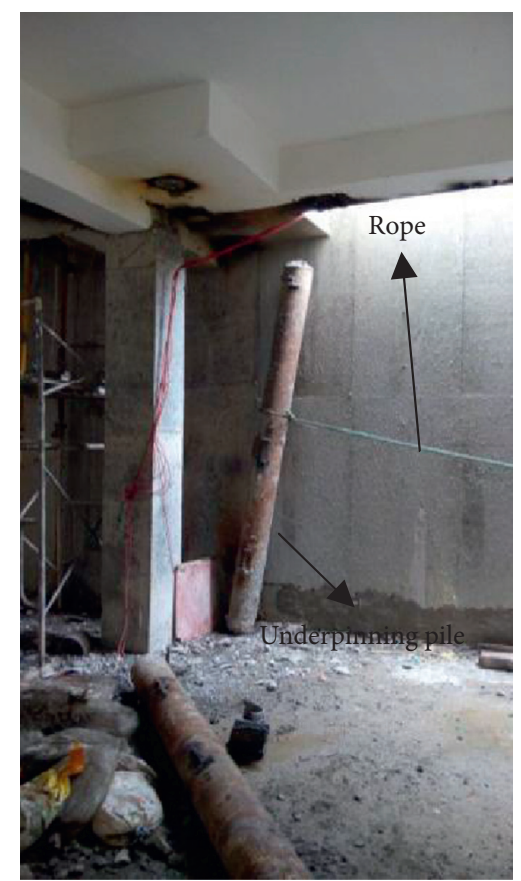

(b)

FIgURE 11: Cutting off the underpinning pile: (a) cutting off the pile; (b) pulling down the pile.

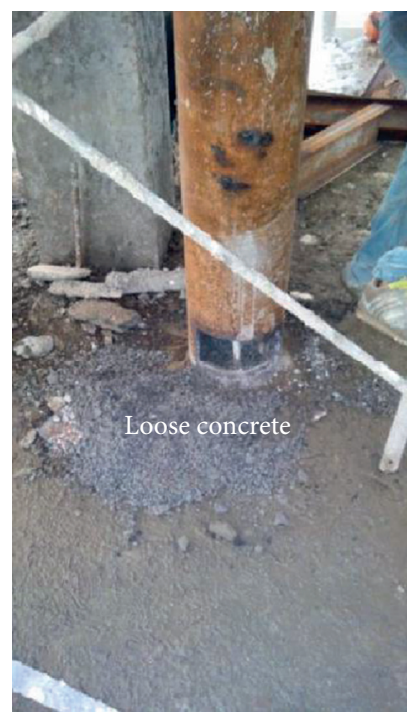

Figure 12: Loose concrete at the pile lower part.

In this paper, it is assumed that the deformation is coordinated between the vibrating wire rebar strain gauge and the steel pipe pile, that is,

$$
\varepsilon_{s g i}=\varepsilon_{i},
$$

where $\varepsilon_{i}$ is the pile strain at the section of the underpinning pile.

Then, the pile axial force at this section is $P_{i}$ :

$$
P_{i}=E_{p} \varepsilon_{i} A_{p},
$$

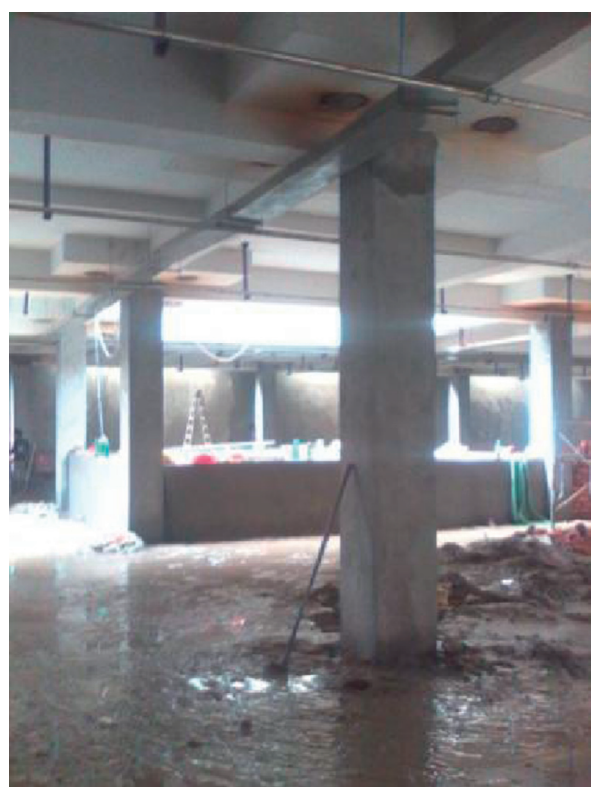

FIGURE 13: Main structure of the new basement.

where $E_{p}$ and $A_{p}$ are the elastic modulus and sectional area of the pile.

\section{Numerical Simulation}

5.1. Soil Model. The in situ monitoring test of excavation beneath existing buildings is not repeatable, and the numerical software such as finite element can well simulate 


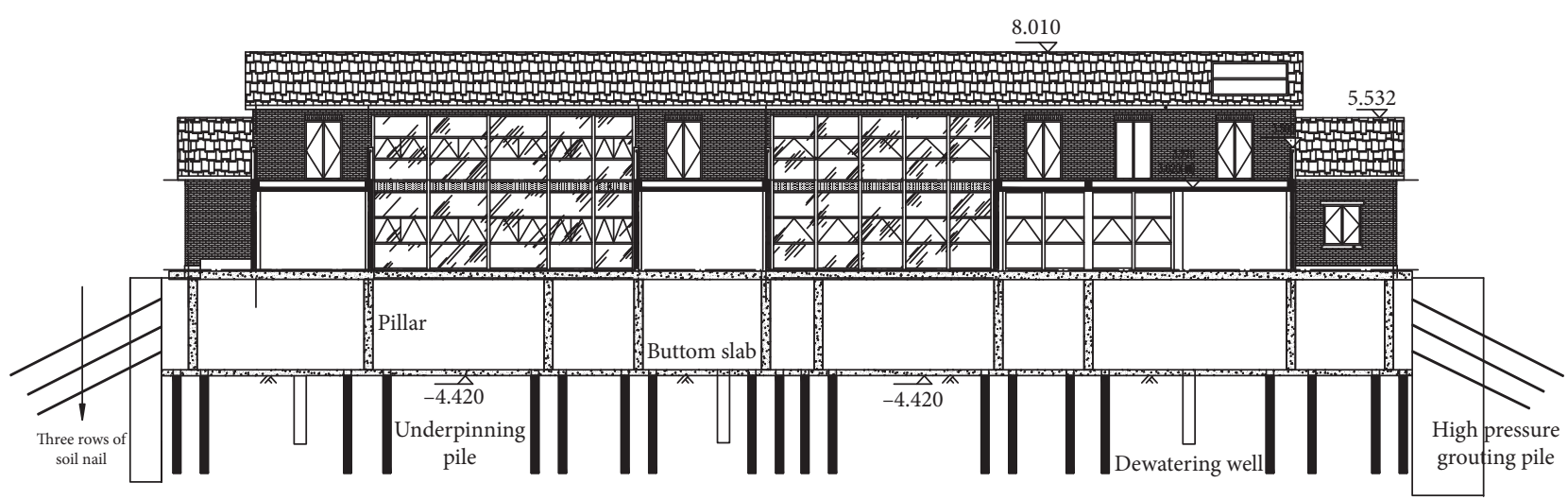

Figure 14: New basement diagram.

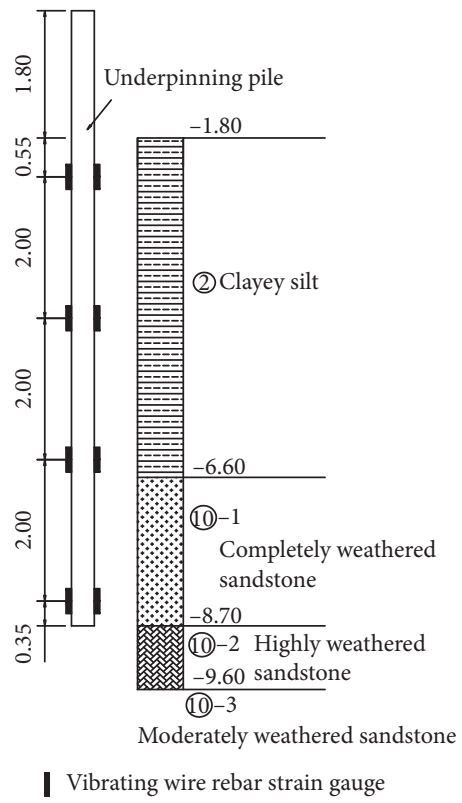

(a)

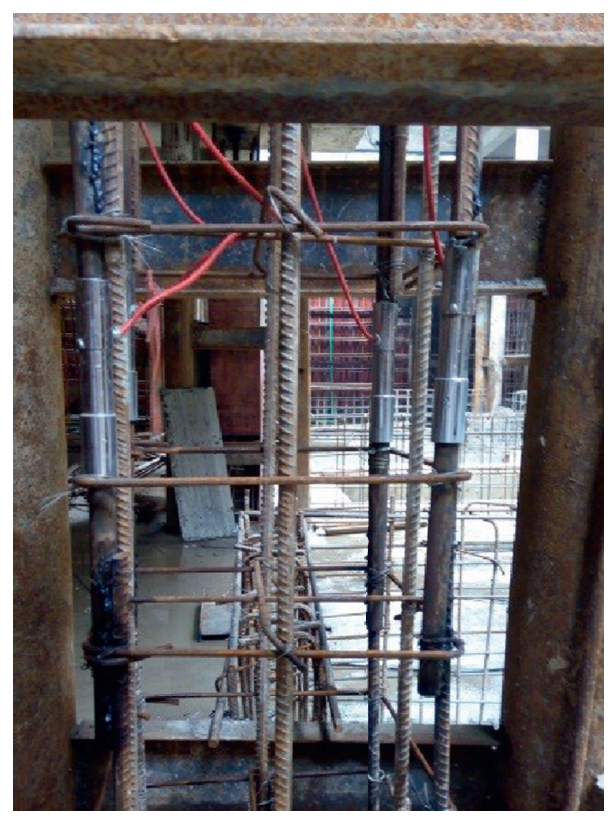

(b)

FIGURE 15: Layouts of vibrating wire rebar strain gauges in underpinning piles and structural pillars at the cap of 7C: (a) layout of vibrating wire rebar strain gauge in the pile; (b) layout of vibrating wire rebar strain gauges in the pillar.

various working conditions. Therefore, using Plaxis 3D geotechnical engineering finite element software, this paper established a 3D solid model of 7C cap-underpinning pileexcavation. It can analyze the influence of different pile cutting sequences on the bearing behavior of new basement structural pillars in projects of excavation beneath existing buildings.

Soil is neither an elastomer nor an ideal elastoplastic body, but a complex elastoplastic body [24]. Burland [25] pointed out that the soil has great stiffness under the condition of small strain, and with the increase of strain, the stiffness presents a nonlinear decrease. Therefore, we use a small strain hardening model to simulate the soil's stressstrain relationship.
5.2. Model Parameter. There are many parameters in the small strain hardening model. Zhang et al. [26] and Fang et al. [27] studied the stress-related stiffness and recommended the relative stiffness of silt and clay as 0.8 and 1.0, respectively.

According to the existing literature [28], the dilatancy angle $\psi$ of sand can be obtained by empirical formula (5), and the dilatancy angle $\psi$ of clay is 0 .

$$
\psi=\mathrm{j}-30 \text {. }
$$

$G_{\text {ref }}^{0}$ and $\gamma_{0.7}$ are the reference shear modulus at the small strain stage and the corresponding shear strain at $G_{s}=0.70 G_{0}$, respectively. The parameters $G_{\text {ref }}^{0}$ and $\gamma_{0.7}$ can be obtained by the following formulae, respectively: 


$$
\begin{aligned}
\gamma_{0.7} & =\frac{1}{9 G_{0}}\left[2 c(1+\cos (2))+\sigma_{1}\left(1+K_{0}\right) \sin (2)\right], \\
G_{0} & =G_{0}^{\mathrm{ref}}\left(\frac{c \cos -\sigma_{1} \sin }{c \cos +p_{\mathrm{ref}} \sin }\right)^{m},
\end{aligned}
$$

where $G_{0}$ is the small strain shear modulus; $K_{0}$ is the static Earth pressure coefficient; $K_{0}=1-\sin \varphi ; \sigma_{1}$ is the main stress.

The strength parameters can be determined by experimental tests, and the stiffness coefficient $E_{50}^{\text {ref }}$ can be obtained by inversion calculation. The remaining parameters can be obtained by the stiffness coefficient $E_{50}^{\text {ref }}$ and similar engineering experience $[26,27,29,30]$, as presented in Table 2.

Based on the in situ measurement data, the load at the top of the $7 \mathrm{C}$ cap is $672.59 \mathrm{kN}$. The concrete strength grade of the original independent foundation of No. 3 section basement construction project of Ganshuixiang is C25. The concrete strength grade of the new basement structural pillar, floor slab, roof, and cap is C35, whose strength coefficient can be found in the specification [22]. The steel pipe pile's elastic modulus is $206 \times 10^{9} \mathrm{kPa}$. In this numerical simulation, we utilize the elastic model to analyze the stressstrain relationship of the concrete structure [31-33] and the underpinning pile.

5.3. Modeling Process. Considering the boundary effect and calculation time, this model selected the cube with the length, width, and height of $40 \mathrm{~m}$, as shown in Figure 16.

Combined with the site construction situation, the following calculation steps are analyzed to simulate the whole project:

(1) The initial stress field of soil is applied.

(2) Activate superstructure loads and isolated foundations. Combined with the field measured data, the superstructure load of the $7 \mathrm{C}$ bearing platform is $672.59 \mathrm{kN}$.

(3) Excavate the first layer of soil to $1.80 \mathrm{~m}$ below the surface, that is, the embedded depth of independent foundation.

(4) Activate the underpinning pile and pile cap to kill the original shallow foundation.

(5) Dig under the soil layer. The excavation is performed four times, with the first three times at an excavation depth of $0.60 \mathrm{~m}$ and the last at an excavation depth of $0.82 \mathrm{~m}$. After that, the new basement floor and structural column are activated.

(6) The underpinning piles are killed and the reconstruction project is completed.

This section mainly studies the influence of clockwise pile cutting and buttress cutting pile on the bearing behavior of new basement structural columns.

\section{Discussion}

This section will discuss the influence of excavation beneath existing buildings on the bearing behaviors of the underpinning pile and new basement structural pillars, and its influence on the superstructure settlement behavior. Simultaneously, the influence of different pile cutting sequences on the bearing capacity of structural pillars is analyzed using the numerical model.

6.1. Bearing Behavior of Underpinning Piles. The excavation beneath existing buildings will break the initial stress balance between the pile and soil. In this project, the influence of excavation depth on the pile axial force is monitored by welding steel stress meters beside the steel pipe pile, as shown in Figure 15. It is worth noting that the soil layer $1.80 \mathrm{~m}$ below the surface has been excavated before the construction of this project. Therefore, the pile axial force within this range remains unchanged and the skin friction is zero.

Figure 17 shows that the underpinning pile's axial force increased with the rise of excavation depth. When the buried depth rose, the pile skin friction began to take effect and the pile axial force reduced with the increase of buried depth. When the excavation depth was $2.50 \mathrm{~m}$, the pile axial forces at 7C cap with buried depths of $2.35 \mathrm{~m}, 4.35 \mathrm{~m}$, and $6.35 \mathrm{~m}$ were $161.9 \mathrm{kN}, 93.86 \mathrm{kN}$, and $25.13 \mathrm{kN}$, respectively. When it developed into $4.42 \mathrm{~m}$, the pile axial forces at different buried depths were $161.9 \mathrm{kN}, 161.9 \mathrm{kN}$, and $113.3 \mathrm{kN}$. The resistance on the pile end was zero in the whole process.

The underpinning pile's skin friction can be obtained by differentiating the distinction of the pile axial force between two sections by the corresponding contact area. Therefore, the pile skin friction obtained in the excavation process is the average value, as illustrated in Figure 18. As is evident, the skin friction of the pile was gradually exerted from top to bottom. Soil excavation is an unloading process, which makes the vertical effective stress gradually decrease. Using the $\beta$ method [34], it is suggested that the pile skin friction in the shallow layer gradually decreases. As the superstructure load of this project remains unchanged, the pile skin friction in the deep layer is gradually exerted.

\subsection{Influence of Pile Cutting on the Bearing Behavior of} Structural Pillars. Structural pillars are an important vertical bearing component. In order to improve the utilization rate of the new basement space, the underpinning piles inside the new basement should be cut off. In the pile cutting process, the existing load transfer behavior is changed, and the load of the superstructure is changed from underpinning piles to new structural pillars. At present, similar basement excavation projects are rare and limited, and the influence of the pile cutting process on the bearing behave of structural pillars has not been reported. Therefore, based on No. 3 section basement construction project of Ganshuixiang, we monitor the impact of the pile cutting process on the bearing capacity of underpinning piles by welding steel stress meters on the main reinforcement of new basement structural pillars, as presented in Figure 19. As it suggests, when the pile cutting number was enlarged, the axial force of the structural pillar increased sharply. For example, when the first underpinning pile was removed, the axial force of the 
TABLE 2: Soil parameters in the numerical analysis.

\begin{tabular}{|c|c|c|c|c|c|}
\hline Soil layer & $E_{50}^{\mathrm{ref}}(\mathrm{kPa})$ & $E_{\text {oed }}^{\text {ref }}(\mathrm{kPa})$ & $E_{\mathrm{ur}}^{\mathrm{ref}}(\mathrm{kPa})$ & $G_{\text {ref }}^{0}(\mathrm{kPa})$ & $\gamma_{0.7}$ \\
\hline Miscellaneous fill & 4200 & 2800 & 10500 & 31500 & 0.0002 \\
\hline Clay silt & 12600 & 8400 & 31500 & 94500 & 0.0002 \\
\hline Fully weathered sandstone & 18000 & 12000 & 45000 & 135000 & 0.0002 \\
\hline Highly weathered sandstone & 30000 & 20000 & 75000 & 225000 & 0.0002 \\
\hline Moderately weathered sandstone & 60000 & 40000 & 150000 & 450000 & 0.0002 \\
\hline
\end{tabular}

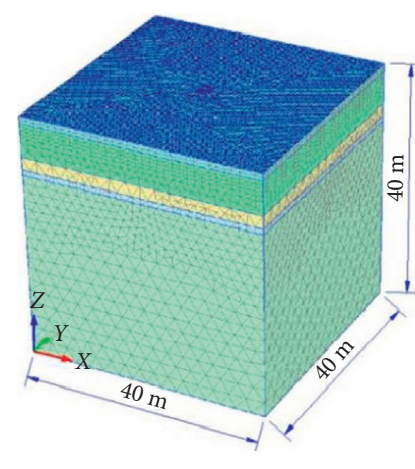

(a)

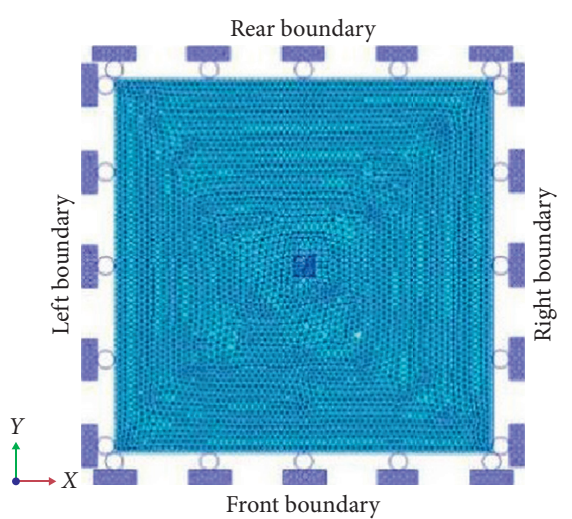

(b)

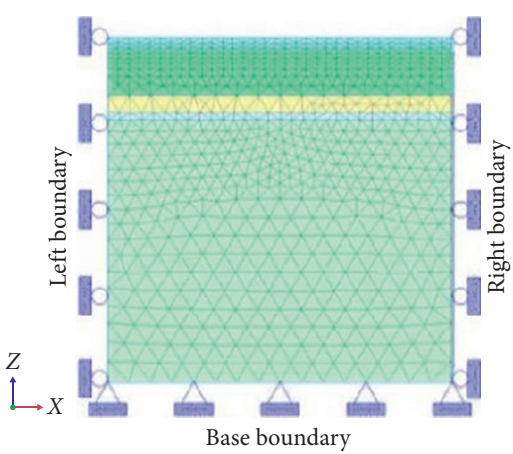

(c)

Figure 16: Three-dimensional model diagram. (a) Grid graph, (b) plane figure, and (c) front view.

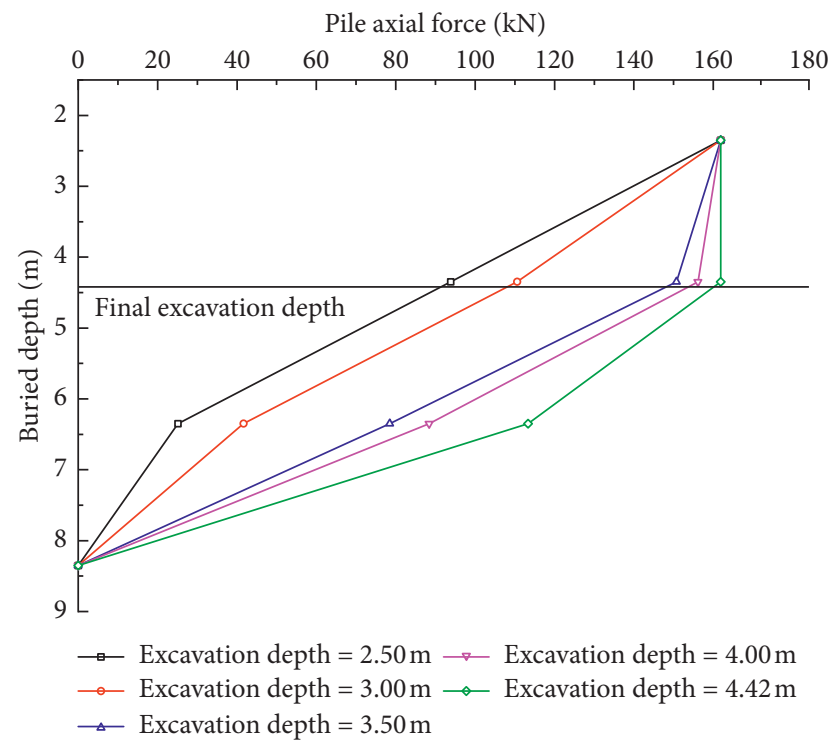

FIGURE 17: Relationship between the excavation depth and axial force of the underpinning pile.

structural pillar increased from $14.67 \mathrm{kN}$ to $90.15 \mathrm{kN}$. It should be noted that when the underpinning pile (3) was removed, the axial force increment of the structural pillar reached the maximum. It may be caused by the sharp decrease in the stiffness of the underpinning pile system. The reason for the above phenomenon should be related to the compressive stiffness of the system, which is composed of underpinning piles and new structural columns.
Different pile cutting sequences may affect the bearing capacity of structural pillars. In this section, Plaxis 3D finite element software was used to establish a 3D solid model of 7C cap-underpinning pile-excavation so as to analyze the influence of different pile cutting sequences on the bearing behavior of structural pillars, as shown in Table 3. In the table, $F_{\mathrm{c} 1} \sim F_{\mathrm{c} 4}$ are the axial force ratios of the structural pillar when the first to fourth piles are removed. They represent the 


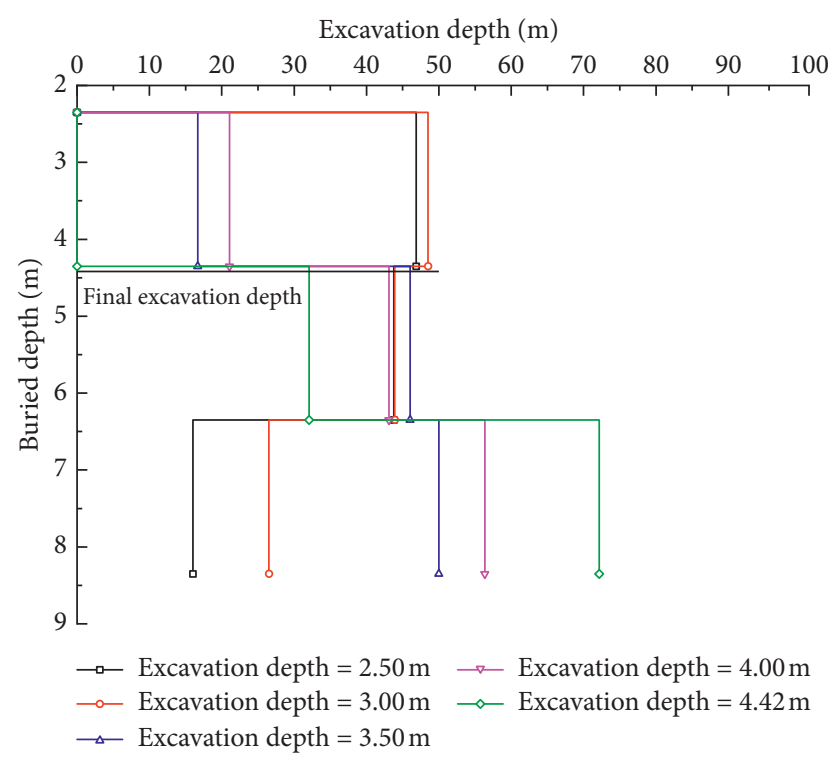

FIGURE 18: Relationship between the excavation depth and skin friction of the underpinning pile.

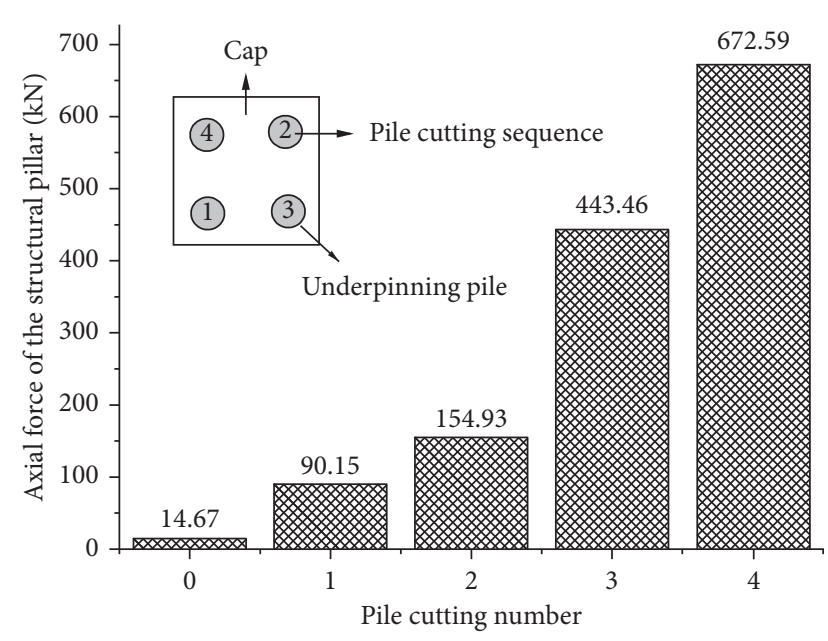

FIGURE 19: Influence of the pile cutting process on the structural pillar's axial force.

TABLE 3: Influence of different pile cutting sequences on the structural pillar's axial force.

\begin{tabular}{lcccc}
\hline & $F_{\mathrm{c} 1}$ & $F_{\mathrm{c} 2}$ & $F_{\mathrm{c} 3}$ & $F_{\mathrm{c} 4}$ \\
\hline Clockwise pile cutting & 0.186 & 0.425 & 0.675 & 1.000 \\
Symmetrical pile cutting & 0.186 & 0.341 & 0.683 & 1.000 \\
In situ data & 0.134 & 0.230 & 0.659 & 1.000 \\
\hline
\end{tabular}

ratio between the axial force of the structural pillar when different numbers of underpinning piles are removed and that when the four underpinning piles are removed. Therefore, $F_{\mathrm{c} 4}=1.000$. As is evident, the axial force of the structural pillar increased sharply with the increase of the pile cutting number, and that different pile cutting sequences would have some impact on the axial force of the structural pillar. For the clockwise pile cutting, the increment peak of the structural pillar's axial force was reached when the fourth underpinning pile was removed. For the symmetrical pile cutting, after the third pile was removed, the increment peak was reached, with a value of 0.342 . Later, when the fourth pile was removed, the increment dropped slightly to 0.317 . It can be seen that different cutting pile sequences have a certain influence on the axial force of new basement structure pillars, and the in situ measured value is close to the result of symmetrical pile cutting sequences. The reason for the above phenomenon may be related to the symmetry of the remaining stiffness after pile cutting. Compared with the symmetrical pile cutting, the clockwise pile cutting is more likely to cause uneven stiffness. That is, after pile cutting is completed, the system of remaining underpinning piles and structural columns will be asymmetrical in stiffness on both sides. Compared with the clockwise pile cutting sequence, the symmetrical pile cutting is more beneficial to the bearing behavior of the new structural column.

6.3. Influence of Excavation on the Settlement Behavior of the Superstructure. Soil excavation will break the existing equilibrium state and result in additional settlement. For projects of excavation beneath existing buildings, when the settlement amount or differential settlement amount is too large, it will have a certain impact on the safety of the superstructure. Therefore, the settlement or differential settlement of the superstructure is an important factor in excavation projects. In this project, 25 settlement monitoring points $(\mathrm{S} 1 \sim \mathrm{S} 25)$ were set on the first floor to monitor the entire construction process, as shown in Figure 20. In the figure, E is soil excavation, CT stands for pouring and curing the concrete floor, CA stands for chiseling away the existing cap and foundation beam, $\mathrm{P}$ means pouring concrete for structural pillars, PC represents the concrete curing period of the structural pillar, and CP is the pile cutting process.

Generally speaking, the settlement monitoring frequency of this project was once every 2 days (except for the 


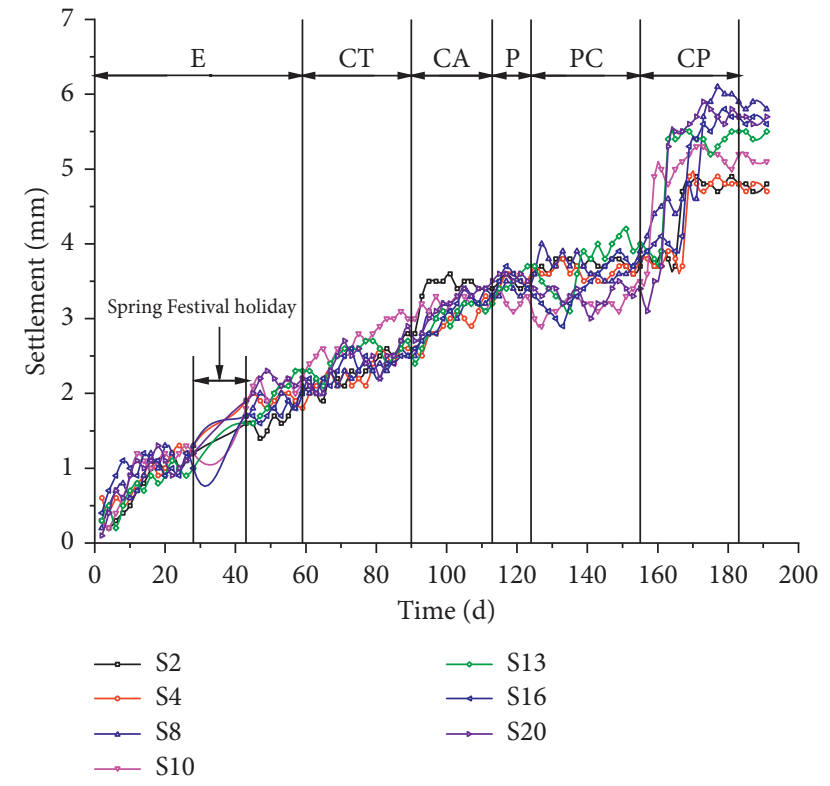

FIgURE 20: Observed profile of in situ settlement.

Spring Festival holiday). It can be seen from the figure that the superstructure of this project had a small settlement, and the maximum settlement was $6.1 \mathrm{~mm}$ (S8 monitoring point). This conforms to the allowable value of building deformation required by the specification [34], indicating that the foundation underpinning structure of this project is reasonable and feasible. In the phase between excavation (E) and pouring concrete for structural pillars $(\mathrm{P})$, the building settlement amount gradually increased over time. The reason may be that the excavation and unloading of the soil have changed the original stress field, and the construction procedures from pouring and curing the concrete floor (CT) to pouring concrete for structural pillars $(\mathrm{P})$ cause a large disturbance to the soil. Thus, the soil is reshaped, and it develops secondary consolidation deformation. In the concrete curing period of the structural pillar (PC), the settlement amount of the building basically remained unchanged. In the pile cutting stage (CP), the settlement of the monitoring point increased by $1-2.3 \mathrm{~mm}$. It is due to the change in the superstructure load transfer mechanism. After the completion of pile cutting, the settlement of the monitoring point decreased to different degrees, which may be related to the redistribution of the superstructure load.

\section{Conclusions}

Based on No. 3 section basement construction project of Ganshuixiang, this paper monitored the basement reconstruction process. Moreover, we used Plaxis 3D finite element software to explore the influence of different pile cutting sequences on the bearing behavior of structural pillars. Some conclusions can be drawn as follows:

(1) In No. 3 section basement construction project of Ganshuixiang, the axial force of the underpinning pile increased with the rise of excavation depth and decreased with the expansion of buried depth. The skin friction of underpinning piles was gradually exerted from top to bottom. The resistance on the pile end was always zero in the whole reconstruction process.

(2) The settlement of the superstructure increased over time. However, in the pile cutting process, the settlement of the building increased sharply. After the completion of pile cutting, the settlement gradually converged. In the storey adding and reconstruction, the superstructure settlement was related to the working condition of digging and adding layers. In the stage of E-PC, the settlement of the superstructure increased slowly with time and tended to be stable at PC. However, in the CP stage, the superstructure settlement increased sharply. After pile cutting, it became stable.

(3) The structural pillar's axial force increased significantly with the increasing pile cutting number. Especially when the underpinning pile (3) was removed, the structural pillar's axial force increment achieved the maximum value. The structural pillar's axial force was affected by different pile cutting sequences. Compared with the clockwise pile cutting sequence, the symmetrical pile cutting was more advantageous.

\section{Data Availability}

The data used to support the findings of this study are available from the corresponding author upon request.

\section{Conflicts of Interest}

The authors declare that there are no conflicts of interest regarding the publication of this paper.

\section{Acknowledgments}

This study was supported by the Zhejiang Natural Science Foundation Exploration Project (grant no. LQ20E080010), Postdoctoral Science Foundation of Zhejiang Province (grant no. zj20180081), and General Industrial Projects of Taizhou Science and Technology Bureau (grant no. 1801gy22).

\section{References}

[1] E. Sung, H. M. Shahin, T. Nakai, M. Hinokio, and M. Yamamoto, "Ground behavior due to tunnel excavation with existing foundation," Soils and Foundations, vol. 46, no. 2, pp. 189-207, 2006.

[2] R. Zhang, J. Zheng, H. Pu, L. Zhang, and H.-F. Pu, "Analysis of excavation-induced responses of loaded pile foundations considering unloading effect," Tunnelling and Underground Space Technology, vol. 26, no. 2, pp. 320-335, 2011.

[3] R.-J. Zhang, J.-J. Zheng, L.-M. Zhang, and H.-F. Pu, "An analysis method for the influence of tunneling on adjacent loaded pile groups with rigid elevated caps," International Journal for Numerical and Analytical Methods in Geomechanics, vol. 35, no. 18, pp. 1949-1971, 2011. 
[4] C. Liu, Z. Zhang, and R. A. Regueiro, "Pile and pile group response to tunnelling using a large diameter slurry shield-case study in Shanghai," Computers and Geotechnics, vol. 59, no. 59, pp. 21-43, 2014.

[5] G. Zheng, Z.-X. Yan, H.-Y. Lei et al., "Field observation and finite element numerical simulation analysis of effect on adjacent piles due to excavation," Chinese Journal of Geotechnical Engineering, vol. 29, no. 5, pp. 638-643, 2007.

[6] W.-D. Wang and Z.-H. Xu, "Simplified analysis method for evaluating excavation-induced damage of adjacent buildings," Chinese Journal of Geotechnical Engineering, vol. 32, no. 1, pp. 638-643, 2010.

[7] X.-N. Gong, C.-J. Wu, F. Yu et al., "Shaft resistance loss of piles due to excavation beneath existing basements," Chinese Journal of Geotechnical Engineering, vol. 35, no. 11, pp. 1957-1964, 2013.

[8] C.-J. Wu, X.-N. Gong, F. Yu et al., "Pile base resistance loss for excavation beneath existing high-rise building," Journal of Zhejiang University (Engineering Science), vol. 48, no. 4, pp. 671-678, 2014.

[9] C.-J. Wu, X.-N. Gong, K. Fang et al., "Effect of excavation beneath existing buildings on loading stiffness of piles," Chinese Journal of Rock Mechanics and Engineering, vol. 33, no. 8, pp. 1526-1535, 2014.

[10] H.-F. Shan, T.-D. Xia, F. Yu et al., "Settlement of pile groups associated with excavation beneath existing basement," Chinese Journal of Geotechnical Engineering, vol. 37, no. 1, pp. 46-50, 2015.

[11] Q.-Q. Zhang, Test and Theoretical Study on Bearing Capacity Behavior and Settlement of Pile in Soft Soils, Zhejiang University, Hangzhou, China, 2012.

[12] H.-F. Shan, T.-D. Xia, F. Yu et al., "Settlement analysis of building piles associated with excavation beneath existing basement in soft soil," Journal of Central South University (Science and Technology), vol. 47, no. 6, pp. 1995-2000, 2016.

[13] H.-F. Shan, T.-D. Xia, J.-H. Hu et al., "Buckling stability analysis of pile foundation for excavation beneath the basement of existing building," Rock and Soil Mechanics, vol. 36, no. 2, pp. 508-512, 2015.

[14] H.-F. Shan, T.-D. Xia, F. Yu et al., "Buckling stability analysis on critical load of underpinning pile for excavation beneath existing building," Journal of Zhejiang University (Engineering Science), vol. 50, no. 8, pp. 1425-1430, 2016.

[15] C.-H. Qiu, Y.-Q. Zhan, Y.-K. Qin et al., "Structural design for renovation and extension of Beijing music hall," Building Science, vol. 15, no. 6, pp. 28-32, 1999.

[16] Y.-W. Wen, S.-Y. Liu, M.-L. Hu et al., "Deformation control techniques for existing buildings during construction process of basement," Chinese Journal of Geotechnical Engineering, vol. 35, no. 10, pp. 1914-1921, 2013.

[17] B. Simpson, J. Paul, and Vardanega, "Results of monitoring at the British library excavation," Geotechnical Engineering, vol. 167, no. 2, pp. 99-116, 2014.

[18] M. A. Hariri-Ardebili, H. Rahmani-Samani, and M. Mirtaheri, "Seismic stability assessment of a high-rise concrete tower utilizing endurance time analysis," International Journal of Structural Stability and Dynamics, vol. 14, no. 6, Article ID 1450016, 2014.

[19] Zhejiang Engineering Geophysical Exploration Institute, Geotechnical Engineering Investigation Report of No. 3 Section Basement Construction Project of Ganshuixiang, Zhejiang Engineering Geophysical Exploration Institute, Hangzhou, China, 2014.
[20] China Railway Engineering Design Institute Co Ltd, Foundation Reinforcement and Underground Auxiliary Facilities of Endangered Houses in Ganshuixiang, China Railway Engineering Design Institute Co., Ltd, Beijing, China, 2014.

[21] JGJ 120-2012, Technical Specification for Retaining and Protection of Building Foundation Excavations, China Architecture and Building Press, Beijing, China, 2012.

[22] GB 50010-2010, Code for Design of Concrete Structures, China Architecture and Building Press, Beijing, China, 2010.

[23] S. P. Timoshenko and J. N. Gutierr, Elasticity Theory, Higher Education Press, Beijing, China, 2013.

[24] Z.-H. Xu and W.-D. Wang, "Selection of soil constitutive models for numerical analysis of deep excavations in close proximity to sensitive properties," Rock and Soil Mechanics, vol. 31, no. 1, pp. 258-264, 2010.

[25] J. B. Burland, "Ninth Laurits Bjerrum memorial lecture: "small is beautiful"-the stiffness of soils at small strains," Canadian Geotechnical Journal, vol. 26, no. 4, pp. 499-516, 1989.

[26] Z.-M. Zhang, K. Fang, X.-W. Liu et al., "Surrounding ground settlement control of special double-row structure supported foundation pit," Journal of Zhejiang University (Engineering Science), vol. 46, no. 7, pp. 1276-1280, 2012.

[27] K. Fang, Z. Zhang, X. Liu, Q. Zhang, and C. Lin, "Numerical analysis of the behavior of special double-row support structure," Journal of Civil Engineering and Management, vol. 19, no. 2, pp. 169-176, 2013.

[28] R. B. J. Brinkgreve, E. Engin, and W. M. Swolfs, "Plaxis 3D 2012 tutorial manual," Plaxis BV, Delft, The Netherlands, 2012.

[29] W.-D. Wang, H.-R. Wang, and Z.-H. Xu, "Study of parameters of HS-small model used in numerical analysis of excavations in Shanghai area," Rock and Soil Mechanics, vol. 34, no. 6, pp. 1766-1774, 2013.

[30] Z.-M. Zhang, Pile Foundation Engineering, China Architecture and Building Press, Beijing, China, 2007.

[31] Z.-H. Deng, H.-Q. Huang, B.-L. Ye et al., "Mechanical performance of RAC under true-triaxial compression after high temperatures," Journal of Materials in Civil Engineering, vol. 32, no. 8, Article ID 04020194, 2020.

[32] Z.-H. Deng, B. Liu, B.-L. Ye et al., "Mechanical behavior and constitutive relationship of the three types of recycled coarse aggregate concrete based on standard classification," Journal of Material Cycles and Waste Management, vol. 22, pp. 30-45, 2020.

[33] Z. H. Deng, H. Q. Huang, B. Ye, H. Wang, and P. Xiang, "Investigation on recycled aggregate concretes exposed to high temperature by biaxial compressive tests," Construction and Building Materials, vol. 244, Article ID 118048, 2020.

[34] GB 50007-2011, Code for Design of Building Foundation, China Architecture and Building Press, Beijing, China, 2011. 